\title{
Klein's Remdesivir-Nucleobase Synthesis Revisited: Chemoselective Cyanation of Pyrrol-2-carboxaldehyde
}

\author{
Juliana A. dos Santos, ${ }^{a}$ Vinícius R. D. Pereira, ${ }^{a}$ Adilson D. da Silva ${ }^{a}$ and \\ Giovanni W. Amarante ${ }^{\circledR} * a$ \\ ${ }^{a}$ Departamento de Química, Universidade Federal de Juiz de Fora, Campus Martelos, \\ 36036-900 Juiz de Fora-MG, Brazil
}

\begin{abstract}
4-Aminopyrrolo[2,1- $f][1,2,4]$ triazine is a fundamental raw material in the synthesis of remdesivir, which demand has increased due to the tests and potential repositioning of this drug against Coronavirus disease 2019 (COVID-19). Here, three chemical steps route for the preparation of remdesivir's nucleobase is described. Particularly, a highly chemoselective cyanation of Klein's route and successful application of monochloramine prepared from commercial bleach as an $\mathrm{N}$-amination reagent are presented.
\end{abstract}

Keywords: remdesivir's nucleobase, triazine, monochloramine, Klein's route

\section{Introduction}

In view of the urgent need for the availability of the remdesivir 1 imposed by the Coronavirus disease 2019 (COVID-19) pandemic and the synthetic challenges of its production, the scientific community has been dedicated to seek improvements to the complex process of obtaining this broad-spectrum $C$-nucleoside antiviral (Scheme 1). ${ }^{1}$ In this context, the preparation of unnatural nucleobase 4-aminopyrrolo[2,1-f][1,2,4] triazine 2 (Scheme 1), an essential unit of $\mathbf{1}$, is still a challenging task, since only a limited number of synthetic routes is available (Scheme 2). In addition, pyrrolotriazine is a starting material that is early involved in the total synthesis of remdesivir, participating in stages that generally occur with moderate yield.

The oldest route for the preparation of $\mathbf{2}$ was described in $1994^{2}$ and allows access to the pyrrolotriazine base in two steps from the pyrrole-2-carboxaldehyde $\mathbf{3}$ in $28 \%$ overall yield (Scheme 2). In this approach, the first synthetic step has poor chemoselectivity, providing the reactive intermediate 1-aminopyrrol-2-carbonitrile 4 in only $43 \%$ yield, as a ca. 1:1 mixture with the presence of the non-reactive intermediate, pyrrole-2-carbonitrile 5 (obtained in 37\% yield (Scheme 3 )). On the other hand, the pyrrolotriazine formation step was particularly simple, in terms of operational (total reaction time to access the base was short (ca. $8 \mathrm{~h}$ ) and led to reasonable yield).

The 2007 Bayer's route, ${ }^{3}$ which is currently commercially employed in remdesivir's production, is a linear sequence of four steps that uses 2,5-dimethoxytetrahydrofuran $\mathbf{6}$ and tert-butyl carbazate 7 and produced the nitrogenous base in an overall yield of $31 \%$ (Scheme 2). According to Snead and co-workers, ${ }^{3}$ the use of protecting groups and derivatized starting materials contribute to mass inefficiency, and adds to the step-count, decreasing overall yield of the Bayer route.

Recently, Snead and co-workers ${ }^{3}$ described a synthetic proposal of recognized efficiency when compared to Bayer's commercial route (Scheme 2). Beginning from pyrrole 8, the access to the nitrogenous base involves, sequentially, a cyanation step, an amination step followed

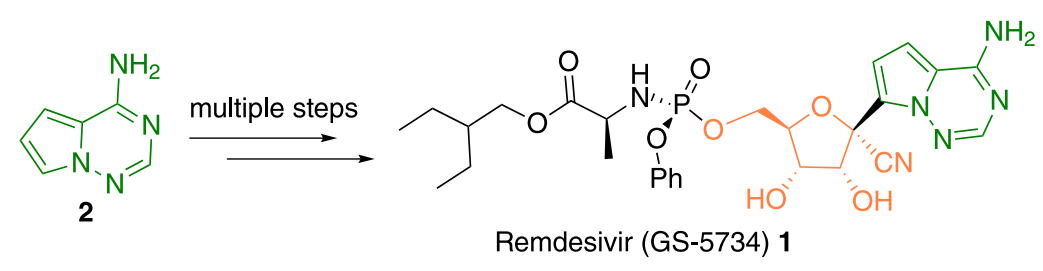

Scheme 1. Remdesivir and pyrrolotriazine chemical structures.

*e-mail: giovanni.amarante@ufjf.edu.br 

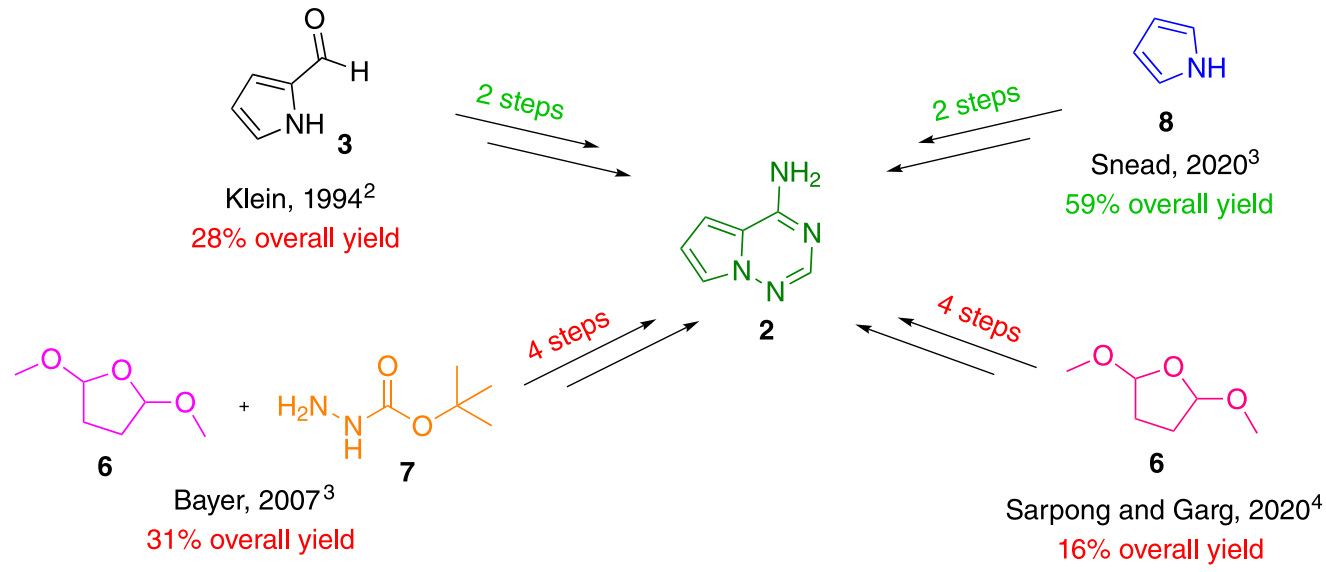

Scheme 2. Available literature ${ }^{2-4}$ routes to achieve 2 .

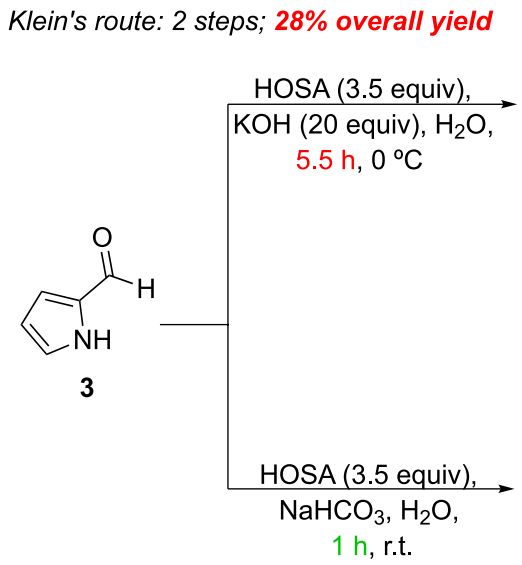

Our route: 3 steps; $39 \%$ overall yield
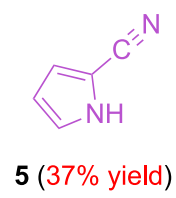

first step: poor chemoselectivity 5: undesired product poor yield to access 4

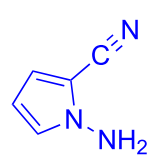

4 (43\% yield)

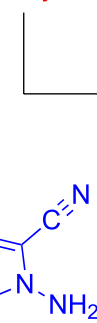

$4(71 \%$ yield $)$

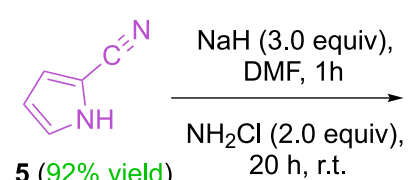

5 ( $92 \%$ yield)
$20 \mathrm{~h}$, r.t.

first step: chemoselective cyanation good and excellent yields to access $\mathbf{4}$ and $\mathbf{5}$

Scheme 3. Klein's remdesivir nitrogen base synthesis, and our approach.

by the formation of $\mathbf{2}$. The overall reported yield is 59\%; the synthesis involves modern approaches such as one pot and flow experiments and has already been described in a gram scale synthesis.

During the development of our work, a fourth synthetic approach was reported in the literature by a collaboration between the Sarpong's and Garg's research groups. ${ }^{4}$ Their strategy has a cyanoamidine cyclization as a key step and provides the nucleobase in $16 \%$ overall yield (Scheme 2). Like Bayer's route, this synthesis requires 2,5-dimethoxytetrahydrofuran compound as the starting material, and a linear sequence of four steps.

Due to that, we were encouraged to revisit the available routes, particularly the one described by Klein. ${ }^{2}$ As a result, a route of three linear steps from pyrrole-2-carboxaldehyde 3 that provides the desired nitrogen base in an overall yield up to $39 \%$ is described (Scheme 3). Our approach solves the problem of poor chemoselectivity in Klein's route, and applies commercial bleach for the generation of the $N$-amination agent monochloramine $\left(\mathrm{NH}_{2} \mathrm{Cl}\right)$.

\section{Results and Discussion}

We carried out our initial experiments investigating the experimental details of the step of $\mathrm{N}$-amination, and conversion of the pyrrole-2-carboxaldehyde $\mathbf{3}$ to nitrile derivative 5 using hydroxylamine- $O$-sulfonic acid (HOSA), as described by Klein. ${ }^{2}$ As a result, we obtained a mixture of the $\mathbf{4}$ and $\mathbf{5}$ in poor yields, in both tested scales (Table 1, entries 1 and 2). Monitoring of the reaction by thin-layer chromatography (TLC), and subsequent analysis of the crude ${ }^{1} \mathrm{H}$ nuclear magnetic resonance (NMR) mixture suggested the presence of a mixture of the two reaction intermediates, probably in the oxime- $O$-sulfonate forms. Alternatively, the addition of an excess of base into this aqueous phase did not promote the formation of the desired products. The reaction monitoring by TLC also indicated that in the first hour only the conversion of $\mathbf{3}$ to $\mathbf{5}$ had occurred. Thus, we evaluated the influence of $\mathrm{KOH}$ concentration/equivalent and the reaction temperature to improve the reaction efficacy and selectivity for obtaining the intermediate 5 (entry 3). This outcome 
Table 1. Optimization and control studies for the first step in the synthesis of 2

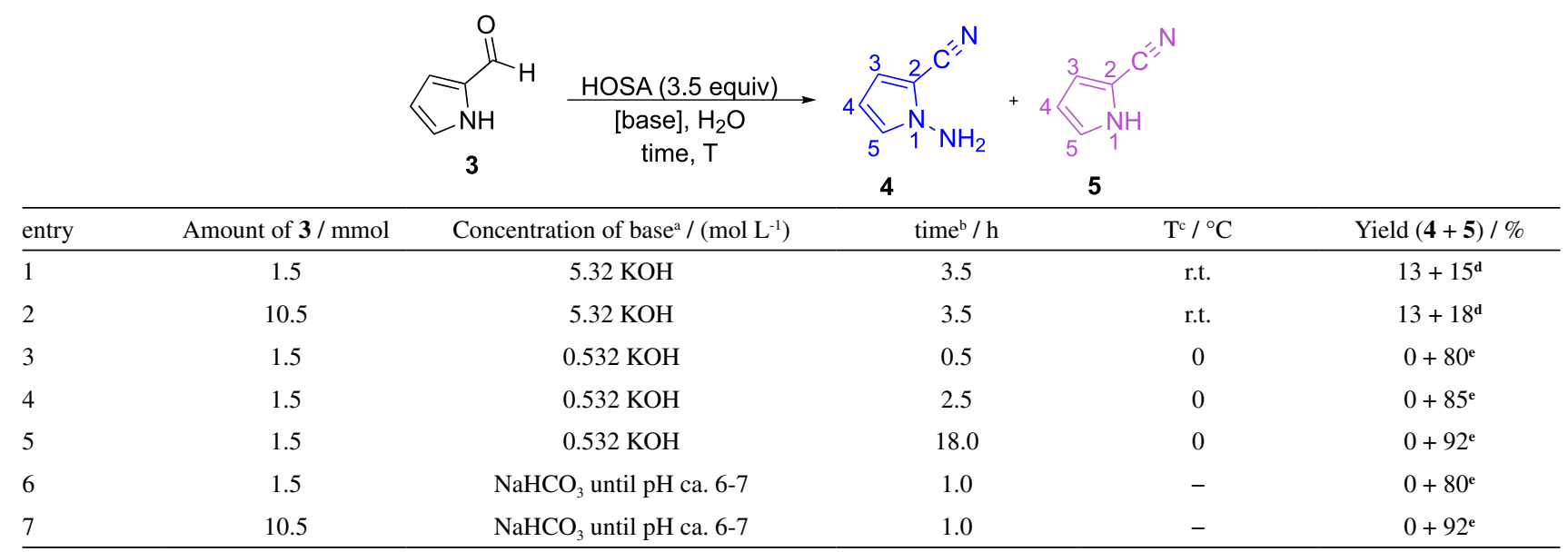

a 20.0 equiv of $\mathrm{KOH}$; ${ }^{b}$ reaction time after base addition; ${ }^{c}$ temperature after base addition; disolated yield after purification through flash chromatography; eyield after liquid-liquid extraction. r.t.: room temperature.

suggested that the use of $0.53 \mathrm{~mol} \mathrm{~L}^{-1}$ of aqueous $\mathrm{KOH}$ solution (instead of $5.32 \mathrm{~mol} \mathrm{~L}^{-1}$ ) is sufficient to promote the selective formation of 5 in up to $92 \%$ yield (entries 3-5). Furthermore, the intermediate $\mathbf{5}$ was satisfactory obtained in $80 \%$ yield in only 30 min (entry 3 ). To comprehend that the performance of the $\mathrm{KOH}$ was restricted to neutralize the cyanation reaction, we investigated the effects of replacing the base by $\mathrm{NaHCO}_{3}$. To our delight, the selective preparation of 5 has been achieved in only $1 \mathrm{~h}$ of reaction at room temperature, followed by neutralization with $\mathrm{NaHCO}_{3}$.

In addition to the reached chemoselectivity, the chromatographic column purification step was eliminated from the process. The pyrrole-2-carbonitrile 5 was obtained in its pure form after only liquid-liquid extraction. The product was isolated in $80 \%$ yield on $1.5 \mathrm{mmol}$ scale (entry 6). Scale up of this cyanation step to $10.5 \mathrm{mmol}$ of the aldehyde provided the desired product in up to $92 \%$ yield (entry 7).

Inspired by the successful cyanation step, we further explored the $\mathrm{N}$-amination with monochloramine, which has been shown to be superior for the electrophilic amination of heterocycles when compared to other $\mathrm{NH}_{2}{ }^{+}$transfer reagents, like HOSA. ${ }^{5}$ Monochloramine can be easily prepared ${ }^{5}$ from inexpensive precursors $\left(\mathrm{NH}_{4} \mathrm{Cl}, \mathrm{NH}_{4} \mathrm{OH}\right.$, $\mathrm{NaOCl}),{ }^{3}$ which is more evident with the use of commercial bleach $\left(\mathrm{NaOCl}_{(\mathrm{aq})}, 2.5-3.5 \mathrm{~m} / \mathrm{m}\right)$. With minor modification of the literature ${ }^{6}$ method (replacing EtOAc by $\mathrm{CH}_{2} \mathrm{Cl}_{2}$ in liquid-liquid extraction) an increase on literature reported yield (from 54 to $71 \%$ ) was achieved, considering different scale experiments (Table 2, entries 1 and 2). Moreover, the recovered starting material can be reused. We also evaluated the effect of the concentration/equivalent amount of the solution of $\mathrm{NH}_{2} \mathrm{Cl}$ in diethyl ether for the efficiency of the transformation (entries 3-4). The results suggested that increasing the equivalents and maintaining the molar concentration the reactivity was not influenced (entry 3 ). Nevertheless, the use of a higher concentration of ethereal solution of $\mathrm{NH}_{2} \mathrm{Cl}$ promoted a subtle adverse effect on the $\mathrm{N}$-amination process (entry 4).

Table 2. Optimization and control studies for the second step: synthesis of 4

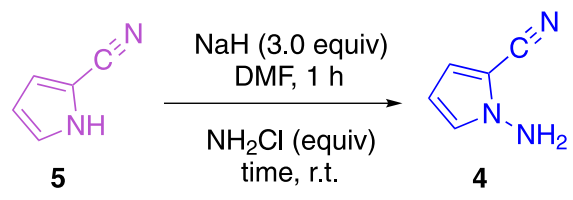

\begin{tabular}{lccccc}
\hline entry & $\begin{array}{c}\text { Amount of 5 / } \\
\text { mmol }\end{array}$ & $\begin{array}{c}{\left[\mathrm{NH}_{2} \mathrm{Cl}\right]} \\
\text { (equiv) / } \\
\left(\mathrm{mol} \mathrm{L}^{-1}\right)\end{array}$ & time / h & $\begin{array}{c}\text { Conversion } \\
\%\end{array}$ & $\begin{array}{c}\text { Yield } \\
\%\end{array}$ \\
\hline 1 & 0.33 & $0.15(2.0)$ & 5.5 & ca. 70 & $\mathrm{NA}$ \\
2 & 9.72 & $0.15(2.0)$ & 21.0 & $>70$ & 71 \\
3 & 9.12 & $0.15(5.0)$ & 21.0 & $>70$ & NA \\
4 & 8.76 & $0.90(2.0)$ & 18.0 & ca. 50 & NA \\
\hline
\end{tabular}

${ }^{\mathrm{a}}$ Conversion calculated from the ${ }^{1} \mathrm{H}$ NMR analysis of crude reaction mixture; bisolated yield after purification through flash chromatography. NA: not available.

For the preparation of pyrrolotriazine, we followed the satisfactory Klein's methodology with minor modifications, thus obtaining similar yields $(60 \%)$ in both reactions scales (1.82 and $6.89 \mathrm{mmol}$ of $\mathbf{4}$ ) (Scheme 3). It is worth mentioning that Snead's approach requires a longer reaction time ( $16 \mathrm{~h}$ ) versus $2.5 \mathrm{~h}$ of Klein's route to reach comparable yield (60\% versus $66 \%$ ).

Finally, the halogenation of $\mathbf{2}$ seems to be particularly important for the remdesivir manufacturing, and the 
halogenated nucleobase $\mathbf{9}$ has been required in recent literature reports. ${ }^{1}$ As an application, the intermediate $\mathbf{2}$ was reacted with $N$-iodosuccinimide (NIS) in dimethylformamide (DMF) to provide the corresponding 7-iodopyrrolo[2,1-f][1,2,4]triazin-4-amine 9 in $47 \%$ yield (Scheme 4). ${ }^{1}$

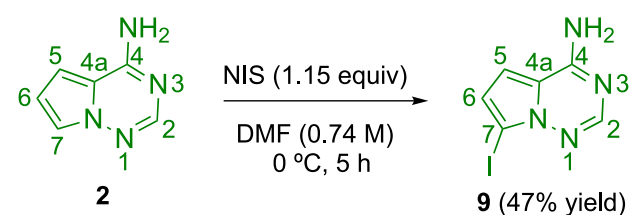

Scheme 4. Synthesis of 9.

\section{Conclusions}

In summary, a synthetic route to access 4-aminopyrrolo[2,1-f][1,2,4]triazine 2 is described. Our approach involves inexpensive and commercially available starting materials allowing to cover the high remdesivir's nucleobase demand. Particularly, after exclusion of hydroxide treatment, a chemoselective cyanation process was achieved, leading exclusively to $\mathbf{5}$. Moreover, commercial bleach was successfully applied in the preparation of monochloramine giving 4 . Together, these experimental changes on Klein's route gave the corresponding remdesivir nucleobase in an overall yield up to $39 \%$. Finally, regioselective halogenation of the nucleobase gave the iodopyrrolotriazine derivative 9 in $47 \%$ yield.

\section{Experimental}

Thin-layer chromatography (TLC) was performed on TLC plates (silica gel $60 \mathrm{~F}_{254}$ ) and visualized by a UV lamp. Column chromatography was performed using 230-400 mesh silica gel. Commercial bleach was purchased from local supermarket $\left(\mathrm{NaOCl}_{\mathrm{aq}}, 2.5-3.5 \mathrm{~m} / \mathrm{m}\right.$, Classic ${ }^{\circledR}$, Juiz de Fora, MG, Brazil). All the other reagents and solvents were purchased from Sigma-Aldrich (Saint Louis, MO, USA), Merck (Darmstadt, Germany), Vetec Química (Duque de Caxias, RJ, Brazil), LabSynth (Diadema, SP, Brazil), and were used without further purification.

The ${ }^{1} \mathrm{H}$ and ${ }^{13} \mathrm{C}$ NMR spectra were recorded at 500 and $125 \mathrm{MHz}$, respectively, on Bruker Avance III $500 \mathrm{MHz}$ spectrometer (Bruker do Brasil, Atibaia, SP, Brazil). Chemical shifts for ${ }^{1} \mathrm{H}$ and ${ }^{13} \mathrm{C}$ NMR were reported as $\delta$ (parts per million) relative to residual signals of the solvent $\left(\mathrm{CDCl}_{3}\right.$ or dimethyl sulfoxide (DMSO- $\left.d_{6}\right)$ ). Chemical shifts are reported employing the following peak abbreviation pattern: br, broad; s, singlet; d, doublet; dd, double doublet and $\mathrm{m}$, multiplet. Melting points were recorded on a melting point apparatus (Microquímica MQAPF-301, Palhoça, SC, Brazil).

1-Aminopyrrol-2-carbonitrile (4) and pyrrole-2-carbonitrile (5)

The mixture was prepared according to the literature method. ${ }^{2}$ These compounds were obtained as pale-yellow oils $(0.142 \mathrm{~g}, 1.32 \mathrm{mmol}, 13 \%$ of $\mathbf{4} ; 0.175 \mathrm{~g}, 1.90 \mathrm{mmol}$, $18 \%$ of $\mathbf{5}$ ) from $10.5 \mathrm{mmol}$ of $\mathbf{3}$.

\section{Pyrrole-2-carbonitrile (5)}

Caution: as a general rule, $O$-sulfonylhydroxylamines like HOSA are thermally labile. ${ }^{7}$ Pyrrole-2-carboxaldehyde $\mathbf{3}$ (10.5 mmol, 1.0 equiv) was dissolved in $32.0 \mathrm{~mL}$ of water and then hydroxylamine- $O$-sulfonic acid $(36.78 \mathrm{mmol}$, 3.5 equiv) was added. The mixture was stirred at room temperature for $1 \mathrm{~h}$, when no starting material was detected by TLC analysis. The yellow-colored solution was cooled to $0{ }^{\circ} \mathrm{C}$ (ice bath) and treated by the $\mathrm{NaHCO}_{3}$ portion additions until $\mathrm{pH}$ ca. 6-7. Then, the reaction was extracted several times with $\mathrm{CH}_{2} \mathrm{Cl}_{2}$. The organic phases were dried with anhydrous $\mathrm{Na}_{2} \mathrm{SO}_{4}$, filtered, and concentrated under reduced pressure. The resulting material $\mathbf{5}$ was obtained in pure form as an oil and did not require further purification (0.895 g, $9.72 \mathrm{mmol}, 92 \%) .{ }^{1} \mathrm{H}$ NMR $\left(500 \mathrm{MHz}, \mathrm{CDCl}_{3}\right)$ $\delta 9.82$ (br s, 1H), 6.96-6.95 (m, 1H), 6.88-6.87 (m, 1H), $6.26(\mathrm{dd}, 1 \mathrm{H}, J 3.6,1.3 \mathrm{~Hz}) ;{ }^{13} \mathrm{C}$ NMR $\left(125 \mathrm{MHz}, \mathrm{CDCl}_{3}\right.$ ) $\delta 124.0,120.3,115.0,110.0,100.4$. Spectral data is in accordance with that described in the literature ${ }^{8}$ for $\mathbf{5}$.

\section{1-Aminopyrrol-2-carbonitrile (4) using $\mathrm{NH}_{2} \mathrm{Cl}$}

Caution: chloramine is not sufficiently stable for storage and can be disproportionated to $\mathrm{NHCl}_{2}$ and $\mathrm{NCl}_{3}$ (a shock-sensitive compound). ${ }^{3,9}$ To a solution of pyrrole2-carbonitrile 5 ( $9.72 \mathrm{mmol}, 1.0$ equiv) in DMF (5.0 mL), $\mathrm{NaH}$ (29.12 mmol, 3.0 equiv, $60 \%$ in mineral oil) was added in small portions and the mixture was stirred for $1 \mathrm{~h}$ at room temperature. Then, the freshly prepared solution of $\mathrm{NH}_{2} \mathrm{Cl}(19.44 \mathrm{mmol}, 2.0$ equiv $)$ in diethyl ether $(97.5 \mathrm{~mL})^{5}$ was added and the resulting mixture was stirred at room temperature and monitored by TLC and ${ }^{1} \mathrm{H}$ NMR analysis over a period of $20 \mathrm{~h}$. Then, the yellow precipitate was filtered, and the solvent was evaporated. The resulting crude material was diluted with cold water and extracted several times with $\mathrm{CH}_{2} \mathrm{Cl}_{2}$. Then, it was dried with anhydrous $\mathrm{Na}_{2} \mathrm{SO}_{4}$, filtered, and concentrated under reduced pressure. The residue was purified through flash chromatography on silica gel (hexanes/EtOAc $=90: 10$ to 80:20) to give the product 4 as an oil $(0.739 \mathrm{~g}, 6.90 \mathrm{mmol}, 71 \%$ of 4$) ; \mathrm{Rf}=0.8$ (hexanes/EtOAc $=50: 50$ ) and the starting material 5 could 
be recovered. ${ }^{1} \mathrm{H}$ NMR $\left(500 \mathrm{MHz}, \mathrm{CDCl}_{3}\right) \delta$ 6.93-6.91 (m, 1H), 6.69 (dd, 1H, J 4.3, $1.7 \mathrm{~Hz}), 6.07$ (dd, 1H, J 4.3, $3.1 \mathrm{~Hz}$ ), 5.01 (br s, 2H); ${ }^{13} \mathrm{C}$ NMR (125 MHz, $\mathrm{CDCl}_{3}$ ) $\delta 128.2,118.3,113.2,107.4,105.8$. Spectral data is in accordance with that described in the literature ${ }^{2}$ for 4 .

\section{4-Aminopyrrolo[2,1-f][1,2,4]triazine (2)}

The nitrogenous base $\mathbf{2}$ was prepared according to the literature method, ${ }^{2}$ using $\mathrm{Na}_{2} \mathrm{CO}_{3}$ instead of $\mathrm{K}_{2} \mathrm{CO}_{3}$ given our unavailability of the latter and obtained as a brown solid $(0.554 \mathrm{~g}, 4.13 \mathrm{mmol}, 60 \%)$. From $1.32 \mathrm{mmol}$ of 4, the product was obtained in the same yield $(0.142 \mathrm{~g}, 1.06 \mathrm{mmol}$, $60 \%$ ). $\mathrm{mp}>240{ }^{\circ} \mathrm{C}$ (mp literature $\left.236-239{ }^{\circ} \mathrm{C}\right) ;{ }^{1} \mathrm{H}$ NMR (500 MHz, DMSO- $d_{6}$ ) $\delta 7.78$ (s, 1H), 7.69 (br s, 2H), 7.59 (dd, $1 \mathrm{H}, J 2.5,1.5 \mathrm{~Hz}), 6.85(\mathrm{dd}, 1 \mathrm{H}, J 4.3,1.5 \mathrm{~Hz}), 6.59$ $(\mathrm{dd}, 1 \mathrm{H}, J 4.3,2.5 \mathrm{~Hz}) ;{ }^{13} \mathrm{C}$ NMR $\left(125 \mathrm{MHz}\right.$, DMSO- $\left.d_{6}\right)$ $\delta$ 155.6, 147.9, 118.1, 114.4, 110.1, 101.2. Spectral data is in accordance with that described in the literature ${ }^{2}$ for $\mathbf{2}$.

7-lodopyrrolo[2,1-f][1,2,4]triazin-4-amine (9)

The iodinated derivative 9 was prepared according to the literature method ${ }^{1}$ and obtained as a beige solid $(0.046 \mathrm{~g}$, $0.18 \mathrm{mmol}, 47 \%$, uncorrected) from $0.38 \mathrm{mmol}$ of $2 ; \mathrm{mp}$ $210-211{ }^{\circ} \mathrm{C}$; ${ }^{1} \mathrm{H}$ NMR $\left(500 \mathrm{MHz}\right.$, DMSO- $\left.d_{6}\right) \delta 7.91$ (s, $1 \mathrm{H}), 7.80$ (br s, 2H), 6.99 (d, 1H, J 4.4 Hz), $6.83(\mathrm{~d}, 1 \mathrm{H}$, $J 4.4 \mathrm{~Hz}$ ); ${ }^{13} \mathrm{C}$ NMR (125 MHz, DMSO- $d_{6}$ ) $\delta 155.2,148.6$, $118.3,117.6,104.0,71.3$. Spectral data is in accordance with that described in the literature ${ }^{1}$ for 9 .

\section{Supplementary Information}

Supplementary information (copies of NMR spectra) is available free of charge at http://jbcs.sbq.org.br as PDF file.

\section{Acknowledgments}

We are grateful for generous financial support from CAPES (finance code 001), CNPq, FAPEMIG (CEX APQ 00341-20), UFJF, and Rede Mineira de Química.

\section{References}

1. Working to Supply Veklury ${ }^{\circledast}$ for COVID-19, available at https:// www.gilead.com/purpose/advancing-global-health/covid-19/ working-to-supply-remdesivir-for-covid-19, accessed in March 2021; Siegel, D.; Hui, H. C.; Doerffler, E.; Clarke, M. O.; Chun, K.; Zhang, L.; Neville, S.; Carra, E.; Lew, W.; Ross, B.; Wang, Q.; Wolfe, L.; Jordan, R.; Soloveva, V.; Knox, J.; Perry, J.; Perron, M.; Stray, K. M.; Barauskas, O.; Feng, J. Y.; Xu, Y.; Lee, G.; Rheingold, A. L.; Ray, A. S.; Bannister, R.; Strickley, R.; Swaminathan, S.; Lee, W. A.; Bavari, S.; Cihlar, T.; Lo, M. K.; Warren, T. K.; Mackman, R. L.; J. Med. Chem. 2017, 60, 1648; Vieira, T.; Stevens, A. C.; Chtchemelinine, A.; Gao, D.; Badalov, P.; Heumann, L.; Org. Process Res. Dev. 2020, 24 , 2113; Xue, F.; Zhou, X.; Zhou, R.; Zhou, X.; Xiao, D.; Gu, E.; Guo, X.; Xiang, J.; Wang, K.; Yang, L.; Zhong, W.; Qin, Y.; Org. Process Res. Dev. 2020, 24, 1772; Keutz, T. V.; Williams, J. D.; Kappe, C. O.; Org. Process Res. Dev. 2020, 24, 2362; Wang, M.; Zhang, L.; Huo, X.; Zhang, Z.; Yuan, Q.; Li, P.; Chen, J.; Zou, Y.; Wu, Z.; Zhang, W.; Angew. Chem., Int. Ed. 2020, 59, 20814. For a recent work on drug repositioning for COVID-19, in which also includes a nitrogen nucleobase, see: Clososki, G. C.; Soldi, R. A.; da Silva, R. M.; Guaratini, T.; Lopes, J. N. C.; Pereira, P. R. R.; Lopes, J. L. C.; dos Santos, T.; Martins, R. B.; Costa, C. S.; de Carvalho, A. N.; daSilva, L. L. P.; Arruda, E.; Lopes, N. P.; J. Braz. Chem. Soc. 2020, 31, 1552.

2. Patil, S. A.; Otter, B. A.; Klein, R. S.; J. Heterocycl. Chem. 1994, 31, 781.

3. Paymode, D. J.; Cardoso, F. S. P.; Agrawal, T.; Tomlin, J. W.; Cook, D. W.; Burns, J. M.; Stringham, R. W.; Sieber, J. D.; Gupton, B. F.; Snead, D. R.; Org. Lett. 2020, 22, 7656 and references cited therein.

4. Knapp, R. R.; Tona, V.; Okada, T.; Sarpong, R.; Garg, N. K.; Org. Lett. 2020, 22, 8430.

5. Hynes, J.; Doubleday, W. W.; Dyckman, A. J.; Godfrey, J. D.; Grosso, J. A.; Kiau, S.; Leftheris, K.; J. Org. Chem. 2004, 69, 1368.

6. Xin, M.; Zhang, L.; Tang, F.; Tu, C.; Wen, J.; Zhao, X.; Liu, Z.; Cheng, L.; Shen, H.; Bioorg. Med. Chem. 2014, 22, 1429.

7. Mendiola, J.; Rinco, J. A.; Mateos, C.; Soriano, J. F.; Frutos, O.; Niemeier, J. K.; Davis, E. M.; Org. Process Res. Dev. 2009, $13,263$.

8. Wang, E. C.; Huang, K. S.; Chen, H. M.; Wu, C. C.; Lin, G. J.; J. Chin. Chem. Soc. 2004, 51, 619.

9. Bhattacharya, A.; Patel, N. C.; Plata, R. E.; Peddicord, M.; Ye, Q.; Parlanti, L.; Palaniswamy, V. A.; Grosso, J. A.; Tetrahedron Lett. 2006, 47, 5341.
Submitted: December 18, 2020

Published online: March 18, 2021 